Манана Микадзе

Государственный университет им. А. Церетели в Кутаиси

Факультет образования

Департамент методики обучения

tel.: +995 577458297

e-mail: manana-mikadze@rambler.ru

ORCID ID: https://orcid.org/0000-0001-8490-4813

\title{
Литературные аллюзии и языковые параллели у Николоза Бараташвили и Адама Мицкевича (стихотворение Мерани и поэма Фарис)
}

Ключевые слова: Мицкевич, Бараташвили, Фарис, Мерани

\section{1. Введение}

«Из грузинских романтиков самым большим поэтом и самым большим философом является Николоз Бараташвили» - эти слова профессора Георгия Джибладзе лучше всего выражают гениальность Николоза Бараташвили, который в 26 лет завершил свою бурную и трагическую жизнь, не сумев осуществить свои мечты из-за полученной в гимназии физической травмы, не сумев воплотить в реальность свою великую любовь, хотя Екатерина Чавчавадзе-Дадиани (объект его неразделенной любви) спасла его поэзию от забвения: именно она передала великому грузинскому писателю Илье Чавчавадзе рукопись Бараташвили, благодаря чему фактически вернула грузинской литературе большого поэта, к этому времени, к сожалению, почти уже позабытого.

\section{2. Сравнение с Фарисом Мицкевича}

С Фарисом Адама Мицкевича Николоз Бараташвили, по нашему мнению, мог ознакомиться через русский перевод. Данное обстоятельство навело некоторых ученых (Иона Меунаргия, Кита Абашидзе) на 
мысль, что грузинский Мерани якобы был создан под определенным воздействием поэмы польского поэта. Подобный взгляд на данный вопрос, по нашему мнению, лишен реального основания, в первую очередь хотя бы вследствие того, что эти два произведения по своей художественной форме обнаруживают весьма отдаленное, почти незначительное сходство, в то время как идейное родство бесспорно. Поэтический дух Мицкевича, несомненно, был близок Николозу Бараташвили.

А. Мицкевич посвятил свою поэму польскому ученому Вацлаву Ражевскому, которого постигла такая же судьба, как и героя поэмы. В. Ражевский проводил научные исследования в Аравии, где и погиб. Мицкевич рисует героический образ наездника, которого не страшитничто; Бараташвили же описывает отчаяние своего всадника, находящегося в том состоянии, когда для него ничто на свете не имеет значения и который предпочитает жизни смерть, но смерть осмысленную, принесенную в жертву потомкам.

В Фарисе передано, как бедуин мчится по пустыне. Однако достаточно перечесть оба произведения, хотя бы даже поверхностно, сразу становится очевидным их весьма сильное отличие как в идейном отношении, так и в плане жанра и стиля. В Мерани в образе всадника выступает сам автор. Поэтому стихотворение выполнено не в форме описания и повествования, а в ритме, передающем реальное положение [Асатиани 1975, 206].

Фарис - один из блестящих памятников польской поэзии. Идею данного произведения Мицкевич позаимствовал из арабского предания.

Проблема, выдвинутая в Мерани, не может считаться проблемой в масштабе только лишь одной страны. В данном стихотворении идеи мирового значения развернуты в чрезвычайно национальной форме, с гениальным творческим мастерством - именно в этом и состоит сильная сторона оригинальности Мерани. С другой стороны, в контексте истории мировой литературы считаем тенденциозным утверждение (Г. Асатиани, Г. Джибладзе), что ни одно художественное средство, ни один эпитет в рассматриваемых произведениях не сходны. Мы придерживаемся мнения академика Георгия Джибладзе о том, что здесь «нет никакого влияния, никакого подражания, есть только лишь невольное совпадение отдельных поэтических образов». Мировая литература знает множество примеров подобных фактов, поскольку гении из разных эпох и разных географических ареалов часто мыслят одинаково. При прочтении русского перевода стихотворения французского поэта Сюлли Прюдома (Рене Франсуа Арман Прюдом) Вскачь (написано через 20 лет после Мерани) становится ясно, что по своей теме 
и построению оно весьма близко к Мерани, хотя неизвестно, был ли Сюлли Прюдомзнаком с бессмертным творением грузинского поэта.

Сравним отрывки из произведений нескольких поэтов.

\section{Николоз Бараташвили:}

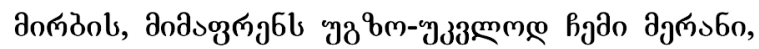

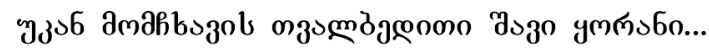

(Мчит, меня несёт без путей-дорог мой Мерани,

Чёрный ворон вслед шлёт проклятья мне с поля брани).

[Перевод с грузинского Ирины Санадзе https://www.stihi.ru/2009/01/29/4993].

\section{Сюлли Прюдом:}

Мчись, мой конь, вздымая искры огненным дождем!

По горам и по долинам вихрем промелькнем.

\section{Адам Мицкевич:}

Шибче! Шибче! Он скользит, До песку едва касаясь.

Дальше! Дальше! Поднимаясь

С вихрем пыли, он летит!..

\section{3. История создания стихотворения}

Стихотворение Мерани было создано в связи с конкретным историческим фактом. В 1842 году в Дагестане отряды горцев взяли в плен дядю Николоза Бараташвили со стороны матери - Илью Орбелиани, офицера Кавказских войск и школьного друга поэта. Мужество и стойкость И. Орбелиани стали примером для подражания. Позднее француженка-гувернантка внуков князя и поэта Александра Чавчавадзе некая Дрансе, которая в 1854-1855 годах также находилась в плену у дагестанцев, рассказала в своих воспоминаниях об услышанной ею в горах истории о судьбе Ильи Орбелиани - о твердости его характера и необычайной смелости. Даже Шамиль, лидер национального движения в Дагестане, оказывается, был поражен мужеством дяди поэта.

Именно данный биографический факт из жизни молодого грузинского офицера и стал тем первоначальным толчком, который вызвал душевное волнение Николоза Бараташвили как человека сильных страстей и способствовал написанию стихотворения Мерани. Он пишет письмо старшему брату Ильи, известному генералу и поэту Григолу Орбелиани, т.е. своему другому дяде, о приключениях его младшего брата в Дагестане и о его судьбе, сопроводив при этом данное пись- 
мо только что написанным стихотворением Мерани (тогда оно еще не имело названия), и добавляет: «Не знаю, понравится ли тебе это стихотворение. Здесь же [в Тифлисе - М.M.] при чтении его пролилось много слез, лжи и правды, потому что об этом говорит находящийся в плену Илья, а не я...» (Письмо датировано 2-ым мая 1842 года).

\section{4. Штрихи к содержанию:}

В Мерани налицо героическое противоборство рассказчика с судьбой. Вслед наезднику, сидящему на крылатом коне, несущемся в бесконечном пространстве, зловеще каркает черный ворон, который возвещает трагический конец. Поэт тоже кричит своему скакуну - просит, чтобы тот вынес его за пределы судьбы. Настолько силен и стихиен бунт Н. Бараташвили против сил судьбы, что он готов поступиться отчизной, родными и даже возлюбленной, готов найти себе могилу среди лугов в чистом поле и под чужим небом, лишь бы не покоряться судьбе. Это есть героический клич-призыв к отказу от реального мира, «безумное стремление» к переходу в космическую сферу, к отказу от всех земных, материальных благ с целью наиболее полного освобождения. Это есть самозабвенное наслаждение самим бегом, стремительным движением вперед. Мрачно волнующиеся мысли поэта представляются нам то как одна цельная энергия, имеющая сходство с бушеванием волн, то развертываются в формах высшей поэтической медитации и в пространных, замедленных, с точки зрения темпа, строфах, становясь по-

хожими на временное успокоение и глухой ропот волн. Мерани - это настоящая симфония, в которой за переданным в энергичном темпе основным мотивом следуют рассуждения о судьбе, об уделе самого поэта и о человеческом долге среди собратьев.

Бараташвили прекрасно использовал общий фон поэмы Мицкевича. По содержанию Фариса никак не скажешь, почему и куда стремится арабский наездник. В стихотворении же Бараташвили намерение героя вполне очевидно: он бежит, он летит, чтобы покинуть отчизну, убежать от человека вообще, от равных себе, от друзей, быть с которыми ему надоело, скачет, чтобы отдать ветру свои мрачно волнующиеся мысли, а стон своего сердца и остатки любви - восторженному, безумному стремлению коня. На арабского скакуна Бараташвили посадил человека с опустошенной душой, у которого нет желания находиться среди людей. Этот конь мчится по бездорожью и везет с собой своего всадника, который противостоит судьбе. 


\section{5. Сравнение в мировой поэзии}

Образ всадника, вступившего в борьбу с препятствиями, в своих различных мировоззренческих модификациях весьма часто встречается в памятниках как грузинской, так и иноязычной литературы. Об этом справедливо замечает грузинский поэт Симон Чиковани: «Начиная с эпической песни Л.Ариосто Неистовый Роланд до лирического стихотворения Сюлли Прюдома Вскачь всадник-храбрец во множестве вариантов мелькает в поэзии» [Асатиани 1975, 207].

Каждое крупное творение в мировой литературе имеет множество поэтических произведений. Также и с Мерани Николоза Бараташвили отдаленно перекликается поэма Адама Мицкевича Фарис, которая, в свою очередь, является отражением восточных поэтических текстов. Ему же родственно стихотворение Пушкина Шуми, шуми, послушное ветрило, являющееся вольным переводом одного отрывка из байроновского Чайльд-Гарольда. Однако все эти совпадения представляют собой совпадения душевного волнения эпохи, а не влияния.

По моему глубокому убеждению, с Мерани перекликается стихотворение Пушкина, переделанное на основе отрывка из Чайльд Гарольда:

Лети, корабль, неси меня к пределам дальним

По грозной прихоти обманчивых морей,

Но только не к брегам печальным

Туманной родины моей...

Параллель С. Чиковани, бесспорно, весьма примечательна. По мнению, Г. Асатиани, здесь же можно было бы вспомнить также и известные лермонтовские строки из «Паруса», которые особенно близки к данному отрывку из поэмы Байрона.

\section{Михаил Лермонтов}

ПАРУС

Что ищет он в стране далекой?

Что кинул он в краю родном?...

Увы! Он счастия не ищет

И не от счастия бежит!

А он, мятежный, просит бури,

Как будто в бурях есть покой!

Следует отметить, что образ мчащегося без путей-дорог коня встречается также и в творчестве Байрона. Исследователи биографии автора Чайльда-Гарольда и его литературного наследия признают наи- 
более блестящим образцом его поэзии то место из поэмы Maзеnа, где описывается именно подобная картина.

Голый Мазепа, привязанный врагами навзничь к спине своего дикого коня, мчится без путей-дорог по необозримой степи. Его разъяренный скакун бурей рассекает пространство, упорно преодолевает тысячи препятствий и в конце концов, выбившись из сил от усталости, падает бездыханным на землю.

П. Ингороква обратил внимание на важное совпадение между $B u$ тязем в тигровой шкуре и Мерани [Ингороква 1969, 15]. Самоотверженный наездник Николоза Бараташвили говорит:

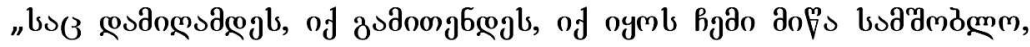

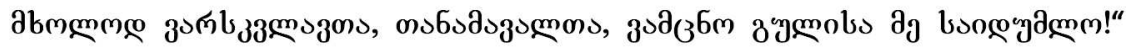

«Будет там мой дом, где настигнет сон, где с зарёй ранним утром встану, Лишь попутчицам-звёздам открою всё - им свою расскажу тайну!»

[Перевод с грузинского Ирины Санадзе [https://www.stihi.ru/2009/01/29/4993].

То же самое говорит и Руставели об Автандиле, который жертвует собой ради друга:

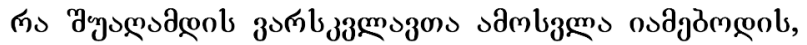

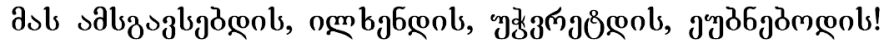

«Какая полночная восходящая звезда порадовал бы,

Он был похож на нее, посмотрел на нее, сказал ей!»

(Наш интеллектуальный перевод М.М.).

В результате подробного литературного анализа становится очевидным, что между Руставели и Бараташвили, несмотря на радикальное отличие их поэтической природы и художественного стиля, имеются отдельные линии совпадения. У Бараташвили чувствуется стихия поэзии Руставели.

Однако, разумеется, самоотверженный всадник стихотворения Бараташвили Мерани все-таки совершенно другой, чем руставелевский самоотверженный всадник Автандил, так же как другими являются Грузия XII века и Картли эпохи Николоза Бараташвили.

Мерани принадлежит к числу таких произведений, в которых содержание, идея, эмоциональное настроение наиболее полно и исчерпывающе выражены посредством всего формального арсенала поэзии.

Это стихотворение - одно из наиболее блестящих проявлений поэтического гения грузинского народа, имеющее вследствие этого силу непреходящего художественного творчества [Асатиани 1975, 215]. 
По словам Ильи Чавчавадзе, «Байроновский Каин для этого избрал Люцифера, Фауст Гете - Мефистофеля, а Бараташвили - своего Мерани, то есть стремительное движение вперед своей души».

Метафора-аллюзия скакуна и всадника восходит к глубине веков, проходя постепенно несколько ступеней градации. Истоки свои она находит в древнейших верованиях и представлениях, что впоследствии разрешилось в мифопоэтической мыслительной системе, получив параллельно также и астрологическое осмысление.

Скакун (мерани) и наездник, их значение и суть, согласно общекультурным, в частности, мифологическим, фольклорным, философским, богословским и литературным традициям, являются в своем единстве метафорой, энигмой, символом, аллегорией, аллюзией.

Мерани у Бараташвили - это образ-символ, художественный образ; таков же и Фарис у Мицкевича. Заглавие для обоих авторов это заголовок-метафора, который основывается на ассоциативном, контрастном мышлении и в то же время объемлет глубокую эстетическую функцию и пространственно-временную поэтику.

\section{K вопросу о языке}

Автор Мерани часто обращается к тавтологическим и усиливающим поэтическим средствам, его язык по существу удивительно лаконичен и точен. Здесь найдены те единственные слова, те единственные краски и художественные штрихи, которые выражают внутреннюю суть идеи произведения.

Необычайным лаконизмом поэтического выражения притягивают нас уже первые две строчки рассматриваемого стихотворения, в которых нарисована символическая картина:

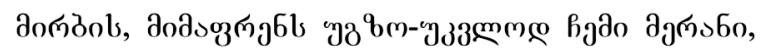
эз

(Мчит, меня несёт без путей-дорог мой Мерани,

Чёрный ворон вслед шлёт проклятья мне с поля брани).

[Перевод с грузинского Ирины Санадзе https://www.stihi.ru/2009/01/29/4993].

Каждый предмет обрисован с чрезвычайной рельефностью, соответственно меняется и звуковая фактура стихотворения, его музыкальное звучание [Асатиани 1975, 214].

Здесь глаголы, выражающие действие одного и того же грамматического залога, благодаря своей настойчивой, сознательно монотонной 
интонации создают в нашем представлении впечатление вечного, постоянного движения вперед.

Архитектоника Мерани, его сложное метрическое построение и система сочетания друг с другом строф различного размера указывают на то, что данное произведение вызревало внутри поэта в течение долгого времени.

Самую большую смысловую нагрузку поэт вложил в глаголы и частицы, придав тем самым посредством этих двух частей речи сверхъестественную силу идее неподчинения судьбе и стремления к лучшему.

Язык Фариса Адама Мицкевича полон эпитетов. Текст поэмы, нагруженный прилагательными и глаголами, прекрасно описывает, как бедуин ищет страну звезд - страну мечты, где человек еще не бывал. Конь бедуина чёрен, как туча, предвещающая грозу, а на лбу у него светит звезда, как дневной свет:

Конь - огонь; мелькают ноги.

Лес и горы! Прочь с дороги!

Эта строфа с небольшими изменениями превращается в рефрен во всей касиде. Фарису на пути попадаются пальма, скалы, коршун, облако, скелеты, ураган. Он одерживает над ними победу, но, летевший в небо вслед за своей мыслью, присоединяется к вечному и сам исчезает в нем. В самоотверженной борьбе Фарис находит личное счастье.

Заголовок стихотворения Мерани - это аллюзия. Аллюзия в общих чертах охватывает субъективное мировидение и ориентируется на образованность читателя, поскольку для реципиента она является языковым средством с целью прочтения в художественном произведении образа мира, увиденного и воспринятого автором.

\section{7. Для выводов}

Гениальность автора Мерани проявляется именно в том, что в суровой, мрачной атмосфере своего времени он все-таки сумел разглядеть, что человек в будущем все равно одержит победу,что придёт время и справедливость восторжествует: будет праздник и на его улице. Н. Бараташвили смог объединить разум и веру, а в их самоотверженном, титаническом противоборстве со слепым роком увидел высший смысл и оправдание существования человека.

Мерани для всей грузинской поэзии является таким же венцом, как и Витязь в тигровой шкуре Шота Руставели. Если в поэме Руставели 
свое наиболее полное отражение нашло классическое эпическое мышление, то Мерани - это блистательный образец лирического самовыражения, свойственного романтической поэзии.

\section{Литература}

Asatiani G., 1975, Nikoloz Baratašvili, (na gruzinskom âzyke), Tbilisi. [Асатиани Г., 1975, Николоз Бараташвили, (на грузинском языке), Тбилиси.]

Baratašvili N., 1980, Stihotvoreniâ, (na gruzinskom âzyke), Tbilisi. [Бараташвили Н., 1980, Стихотворения, (на грузинском языке), Тбилиси.]

Gacereliâ A., 1968, Nikoloz Baratašvili, (na gruzinskom âzyke), Tbilisi. [Гацерелия А., 1968, Николоз Бараташвили, (на грузинском языке), Тбилиси.]

Džibladze G., 1968, Poètičeskijgenij Baratašvili, iz-o «Sabčota Sakartvelo», (na gruzinskom âzyke), Tbilisi. [Джибладзе Г., 1968, Поэтический гений Бараташвили, из-о «Сабчота Сакартвело», (на грузинском языке), Тбилиси.]

Ingorokva P., 1969, Nikoloz Baratašvili, (na gruzinskom âzyke), Tbilisi. [Ингороква П., 1969, Николоз Бараташвили, (на грузинском языке), Тбилиси.]

Meunargiâ I., 1968, Žizn’ i poèzî̂ N. Baratašvili, (na gruzinskom âzyke), Tbilisi. [Меунаргия И., 1968, ЖКизнь и поэзия Н. Бараташвили, (на грузинском языке), Тбилиси.]

Mickevič A., 1913, Sobranie sočinenij, t. 1, Tbilisi. [Мицкевич A., 1913, Собрание сочинений, т. 1, Тбилиси.]

Natrošvili G., 1968, Nikoloz Baratašvili, (na gruzinskom âzyke), Tbilisi. [Натрошвили Г., 1968, Николоз Бараташвили, (на грузинском языке), Тбилиси.]

Čikovanis., 1963, Izbrannye, (na gruzinskomâzyke), Tbilisi. [Чиковани C., 1963, Избранные, (на грузинском языке), Тбилиси.]

https://www.stihi.ru/2009/01/29/4993

\section{LITERARY ALLUSIONS AND LINGUISTIC PARALLELS BY NIKOLOZ BARATASHVILI AND ADAM MITSKEVICH (POEM MERANI AND POEM FARIS)}

ABSTRACT

Key words: Mitskevich, Baratashvili, Faris, Merani

"Of the Georgian romantics, the greatest poet and the greatest philosopher is Nikoloz Baratashvili" - these words of Professor Giorgi Dzhibladze best express the genius of Nikoloz Baratashvili, who at the age of 26 ended his turbulent and tragic life, having failed to fulfill his dreams because of the physical trauma, unable 
to embody her great love in reality, although Ekaterina Chavchavadze-Dadiani (the object of his unrequited love) saved his poetry from oblivion: it was she who gave the great Georgian writer Ilya Chavchavadze Baratashvili's manuscript, thanks to which she actually returned the great poet's Georgian literature to this time, unfortunately, is almost forgotten.

In our opinion, Nikoloz Baratashvili could get acquainted with Faris by Adam Mitskevich through Russian translation. This circumstance led some scholars (Iona Meunargia, Kit Abashidze) to believe that the Georgian Merani was allegedly created under a certain influence of the poem of the Polish poet. Such a view of this issue, in our opinion, is devoid of a real foundation, primarily due to the fact that these two works in their artistic form show a very distant, almost insignificant similarity, while the ideological relationship is indisputable. The poetic spirit of Mitskevich was undoubtedly close to Nikoloz Baratashvili.

A. Mitskevich dedicated his poem to the Polish scientist Vaclav Razhevsky, who suffered the same fate as the hero of the poem. V. Razhevsky conducted scientific research in Arabia, where he died. Mickiewicz paints a heroic image of a rider who is not afraid of anything; Baratashvili, on the other hand, describes the despair of his rider, who is in a state when nothing in the world matters to him and who prefers death to life, but meaningful death, sacrificed to descendants.

The genius of the author of Merani is manifested precisely in the fact that in the harsh, gloomy atmosphere of his time, he still managed to discern that a person in the future will still win, that the time will come and justice will triumph: there will be a holiday on his street. N. Baratashvili was able to unite reason and faith, and in their selfless, titanic confrontation with blind fate, he saw the highest meaning and justification of human existence.

Merani for all Georgian poetry is the same crown as The Knight in the Panther's Skin by Shota Rustaveli. If classic epic thinking found its fullest reflection in Rustaveli's poem, Merani is a brilliant example of lyrical self-expression characteristic of romantic poetry. 